\title{
RENAŞTEREA ÎNVĂŢĂMÂNTULUI BIZANTIN ÎN TIMPUL DINASTIEI MACEDONENE (867-1028)
}

Marius Telea*

\begin{abstract}
The Renaissance of the Byzantine Education in the Macedonian Dynasty (867-1028) One can say that Byzantine culture in the Macedonian epoch evolved under the influence of the measures of reorganisation of higher education of Caesar Bardas (863), who constituted the starting point of what was subsequently named the first Byzantine humanism. The new cultural movement was also connected to the personality of patriarch Photius in the $I X^{\text {th }}$ century, to Emperor Constantine VII Porphyrogennetus in the $X^{\text {th }}$ century and to Michael Psellos, in the XI ${ }^{\text {th }}$ century. Under the influence of these great personalities, the period witnessed the most prominent manifestations of the features which were specific to the Byzantine culture, expressed in the development of a more intimate relation between the profane and the theological elements or in the reconciliation of the ancient pagan wisdom to the new ideas of Christianity, as well as in the development of the general and encyclopedic knowledge. During this period, the University in Constantinople was again a centre of culture and education around which the most important cultural forces of the Empire gathered.
\end{abstract}

Keywords: Macedonians, renaissance, university, culture, education.

\section{Introducere}

Perioada cuprinsă între revenirea lumii bizantine la cultul icoanelor (843) şi moartea împăratului Vasile al II-lea (1025), perioadă ce coincide în liniile sale generale cu guvernarea dinastiei macedonene (867-1028), constituie vârsta de aur a istoriei bizantine, în timpul căreia imperiul de pe Bosfor a atins apogeul puterii sale şi a reuşit să dea măsura originalităţii sale. Perioada a contrastat destul de

\footnotetext{
* PhD, Associate Professor, Faculty of Orthodox Theology at 1 December 1918 University, Alba Iulia, Romania.
} 
mult, din toate punctele de vedere, cu cea precedentă, cunoscută sub numele de epoca luptelor iconoclaste (717-843). Avem de-a face cu o lume profund rurală, cu o administraţie descentralizată, o lume repliată în jurul platourilor anatoliene în încercarea de a supravieţui în faţa expansiunii islamice şi care a renunţat la orice veleităţi thalassocratice, cu o ideologie ale cărei principale valori erau patria şi credinţa ortodoxă. Această lume avea să cedeze locul, către mijlocul secolului al IX-lea, unei societăţi urbanizate, deschisă marilor curente economice ce animau spaţiul mediteranean, cu o politică expensionistă în Orient ca şi în Balcani, legitimată de o ideologie ce a revenit la doctrina constantiniană a imperiului universal.

Perioada a fost inaugurată de domnia lui Mihail al III-lea (842-867), ultimul împărat din dinastia amoriană (820-867), a cărui guvernare, prin problemele ei, a anunţat apogeul statului bizantin. Fondatorul dinastiei macedonene este Vasile I (867-886), provenit dintr-o familie de condiţie modestă, de origine armeană, colonizată de împăratul Nichifor I (802-811) în thema Macedoniei. El a ajuns în fruntea Imperiului după o strălucită carieră în metropola bizantină, ale cărei principale etape s-au consumat ca favorit al împăratului Mihail al III-lea - grăjdar, parakimomenos şi, apoi, caesar - după care a uzurpat tronul protectorului său. Sub noua dinastie, ajunsă la tron în urma unei uzurpări, principiul ereditar a câştigat teren în dauna celui electiv, niciodată abandonat în teorie, prin introducerea instituţiei porphyrogenet-ilor, care desemna descendenţii imperiali născuţi în camera de purpură (porphyra). Acestora le era rezervată succesiunea la tron încă de la naştere, pe această cale coroana imperială păstrându-se într-o singură familie. Consolidat şi de continuitatea dinastică, tronul transmiţându-se din tată în fiu - Vasile I, Leon la VI-lea Filosoful (886-912), Alexandru (912-913), Constantin la VII-lea Porphyrogenetul (913-959), Roman al II-lea (959-963), Vasile al II-lea (976-1025) - pe parcursul a cinci generaţii, sentimentul legitimităţii dinastice şi-a dat întreaga măsură sub minoratul lui Constantin al VII-lea şi Vasile al II-lea, când din raţiuni de stat, au fost adoptaţi la tron generali capabili - Roman I 
Lecapenos (920-944), Nichifor al II-lea Phocas (963-969) şi Ioan I Tzimiskes (969-976) - fără ca prerogativele împăraţilor legitimi să fi suferit vreo atingere.

Epoca dinastiei Macedonene a fost marcată printr-o activitate intensă în domeniul ştiinţelor, literelor, învăţământului şi artei. În general, cultura bizantină din această perioadă a evoluat sub înrâurirea măsurilor întreprinse de cezarul Bardas (863) care aveau să constituie punctul de plecare a ceea ce s-a numit primul umanism bizantin. Noua mişcare culturală a fost legată de personalitatea patriarhului Fotie (c. 820-891), în secolul al IX-lea, precum şi de cea a împăratului-cărturar Constantin al VII-lea Porfirogenetul, în secolul al X-lea şi a lui Mihail Psellos (1018-1078), în secolul al XI-lea, strălucirea lor intelectuală, reînnoirea şcolii superioare reorganizată în secolul al XI-lea, au creat condiţii favorabile renaşterii culturale din epoca Comnenilor şi Anghelilor ${ }^{1}$.

\section{I. Învăţământul epocii macedonene}

O societate cultivată precum cea bizantină presupune existenţa unui învăţământ public foarte bine organizat. $\mathrm{Cu}$ toate acestea nu existau autorităţi care să reglementeze un curriculum ce trebuia urmat de profesori. Ei aveau o mare libertate în acest sens, criteriul după care se stabilea programa de studiu fiind cerinţele venite din partea societăţii. De obicei şcoala elementară începea la 6 ani, iar la 9-10 ani şcolarul putea sa treacă în grija gramaticului. Elevii se dedicau studiului retoricii de la 14 ani la 18 ani. $\mathrm{Nu}$ lipseau copii-minune nici cazurile de studii întrerupte sau efectuate la vârste

${ }^{1}$ A. A. Vasiliev, Istoria Imperiului Bizantin, traducere şi note de IonuţAlexandru Tudorie, Vasile-Adrian Carabă, Sebastian Laurenţiu-Nazâru, studiu introductiv Ionuţ-Alexandru Tudorie, Iaşi, Edit. Polirom, 2010, p. 372. 
înaintate. Adeseori diferenţa de vârstă dintre elevi era o permanentă sursă de probleme pentru dascăl ${ }^{2}$.

Existau în Bizanţ şcoli publice şi private cu niveluri diferite, de la şcolile elementare la facultăţile din cadrul Universităţii.

\section{II. Învăţământul elementar}

Învăţătorul era o persoană simplă, de condiţie socială modestă. Preda citirea şi scrierea şi adeseori noţiuni elementare de aritmetică. Metodele pedagogice erau simple şi nu puneau mare preţ pe dezvoltarea psihologică a copilului. De la bun început, acesta învăţa numele şi forma literelor, apoi, în ordine, silabele mai scurte, morfologia de bază a substantivelor şi verbelor, de obicei fără a ţine seama de variantele arhaice şi dialectale atestate în poezia greacă clasică. Continua apoi să copieze şi să memoreze scurte maxime de tipul: Primeşte sfatul celor inţelepţi, sau $N u$ te increde orbeşte în prieteni. Se trecea, pe urmă, la memorarea unor mici texte în proză, Fabulele lui Esop, însoţite de explicaţiile gramaticale şi morale ale dascălului. Lecturile acestea erau în mod obişnuit consolidate prin pedepse corporale. Cărţile de citire (ca, de altfel, toate cărţile) erau foarte rare şi scumpe. Mai trebuie precizat că numai o mică parte din cei ce făceau faţă şcolii elementare îşi continuau studiile ${ }^{3}$.

\section{Activitatea gramaticului}

Gramaticul îi învăţa pe elevii săi să citească, să înţeleagă şi uneori să evalueze critic literatura Greciei antice. Începea cu predarea morfologiei complexe a substantivului şi a verbului, luând ca material didactic această literatură şi cobora până în detaliu, mult mai mult decât învăţătorul, menţionând numeroasele excepţii de la

\footnotetext{
${ }^{2}$ Robert Browning, Dascălul, în Omul bizantin, volum coordonat de Guglielmo Cavallo, traducere de Ion Mircea, postfaţă de Claudia Tiţa-Mircea, Iaşi, Edit. Polirom, 2000, p. 120.

${ }^{3}$ Ibidem, p. 113-114.
} 
regulă. Acest lucru necesita studierea numeroaselor dialecte adevărate sau presupuse - în care era scrisă literatura, pe lângă cuvintele rare, de uz exclusiv literar. Cum greaca vorbită în viaţa de zi cu zi se deosebea de cea a literaturii clasice greceşti, gramaticul era constrâns să corijeze şi să purifice vorbirea elevilor săi, insistând ca în orice tip de comunicare formală să se recurgă la cuvinte şi expresii pe care nu şi le însuşiseră în copilărie.

Se foloseau manuale antice (Arta gramaticii a lui Dionysios Thrax a fost scrisă în secolul II î. Hr., dar se folosea şi în Evul Mediu) care abordau părţile discursului, morfologiei, etimologiei, figurile semantice şi lexicale.

În paralel cu învăţământul teoretic se proceda la lectura practică a textelor literare. Erau preferate textele poetice, fie pentru că erau mai uşor de memorat, fie că prin natura lor conţineau un număr foarte mare de forme insolite, dincolo de aluzii mitologice sau de alt tip. Mai ales poemele homerice constituiau piesele de rezistenţă ale profesiei de gramatic. Gramaticul sacrifica o bună parte din timpul său cu explicaţia detaliată (cuvânt cu cuvânt, vers cu vers) a Iliadei şi Odiseei sau (mai rar) a lui Hesiod.

În general, elevii nu aveau copii după tratatele de gramatică, pentru a nu mai vorbi de poemele homerice. Gramaticul dicta elevilor fragmentele care urmau să fie memorate; apoi le explica limitându-se adeseori la citirea lor, sau cel mult, la parafrazarea comentariului unuia dintre predecesorii săi - poate chiar al propriului dascăl. În continuare verifica cunoştinţele elevilor, chestionându-i asupra subiectului lecţiei. Progresele elevilor erau, desigur, lente. În secolul al XII-lea, porţia zilnică de Homer consta dintr-un fragment de vreo treizeci de versuri, pe care elevii erau obligaţi să-l înveţe şi să-1 explice ${ }^{4}$.

${ }^{4}$ Ibidem, p. 214-215. 


\section{Organizarea cursurilor de retorică}

Retorul prelua discipolii gramaticului când aceştia aveau înjur de paisprezece ani. El îşi instruia elevii să-şi exprime cu eleganţă şi convingere gândul, pe cale orală sau scrisă. Trebuie să ţinem seama de faptul că într-o cultură în mare parte orală, capacitatea de a vorbi bine era mai importantă şi mult mai apreciată decât în zilele noastre.

Pentru lecţiile de retorică, profesorul se folosea de o culegere progymnasmata sau de exerciţii preliminare: scurte texte-model care ilustrau diferite genuri de compoziţie. Fiecare text-model era precedat de o scurtă definiţie care expunea caracteristicile genului în cauză. Mult timp a fost urmat modelul antic, potrivii căruia se începea cu fabula, se continua cu naraţiunea, cu chreiai (anecdotă ilustrativă, susţinută de câteva aserţiuni cu caracter general), maxima morală, refuzul, confirmarea, locul comun, elogiul, reproşul, comparaţia, personificarea, descrierea, întrebarea de ordin general şi proiectul de lege.

Au existat tendinţe de compunere a unor progymnasmata în care interesele elevilor să fie implicate mult mai direct. În secolul al XII-lea Nichifor Basilakes a compus o nouă culegere în care respectă dispunerea tradiţională a temelor, dar nu furnizează nici o definiţie, lăsând-o pe seama intervenţiei orale a dascălului. El introduce şi o nouă listă de autori pe care cei ce studiau retorica erau obligaţi să-i citească cu exemple de stil supraîncărcat de înflorituri. $O$ altă inovaţie importantă este recursul ocazional la materialul creştin.

Pe la sfârşitul secolului al XI-lea a apărut aşa-numita schedografie. Ea conta din folosirea unor texte de mici dimensiuni, compuse expres de profesor, care se încheiau de multe ori cu un scurt pasaj în versuri. Ele erau dictate elevilor de autor, care le comenta apoi în detaliu. Punctul central al noii metode conta în faptul că textul putea fi construit în aşa fel încât să ilustreze elemente speciale de gramatica, lexicografie, stil şi construcţie, asupra cărora profesorul dorea să concentreze atenţia învăţăceilor săi. Astfel, unele texte schedografice prezentau numeroase exemple de termeni şi 
expresii care sunau identic, dar care aveau semnificaţii diferite, în funcţie de modul cum erau scrise.

După aceste studii preliminare de retorică, elevii treceau la lectura unor oraţii ale lui Demostene sau poate ale lui Libanios. În plus, compuneau discursuri pe teme date de profesor. De obicei erau discursuri avocăţeşti rostite în faţa unei curţi imaginare, pentru un caz imaginar şi sub legi imaginare sau discursuri puse în gura unor personaje istorice din Atena secolelor al V-lea şi al IV-lea î. $\mathrm{Hr}^{5}$.

\section{V. Învăţământul superior}

După moartea împăratului Ioan I Tzimiskes (976) nu mai există alte ştiri sau dovezi despre învăţământul public superior până în anul 1045. Împăratul Vasile al II-lea, un războinic desăvârşit şi un om de acţiune nu pare să fi avut nici timp nici dorinţa de a se interesa de învățământul public.

Mihail Psellos se mira, cum sub domnia unui împărat care într-un fel a dispreţuit ştiinţa, au existat atâţia retori de mare faimă. În ciuda acestor conjuncturi aparent defavorabile dezvoltării învăţământului, putem concluziona că învăţământul public nu a fost într-o stare de profundă letargie. Oameni precum împăratul Roman I Arghyros (1028-1034) sau Mihail Attaliates, care vedea Constantinopolul ca o metropolă universală a ştiinţei, au primit sau au reuşit totuşi în această perioadă să-şi facă o temeinică pregătire în capitală. Apoi există ştiri din acesta perioadă despre o serie de tineri dotaţi provincie, care, pentru aprofundarea studiilor, urmau şcolile particulare din capitală.

În jurul anului 1028, Ioan Mavropos a deschis pe cheltuiala sa o şcoală în capitală. Din biografia lui nu ştim cum a reuşit să-şi însuşească ştiinţa enciclopedică pe care o poseda la un nivel aproape desăvârşit, dar ştim că avea mare popularitate şi trecere în rândul savanţilor vremii. Ceea ce mai ştim este faptul că această şcoală funcţiona în propria sa casă. El petrecea foarte mult timp cu ucenicii

${ }^{5}$ Ibidem, p. 116-120. 
săi, iar discuţiile pe diferite teme se prelungeau de multe ori până în zori. Mai târziu a reuşit să angajeze mai mulţi profesori şi nu percepea nici o taxă studenţilor cursanţi. Lecţiile aveau un vădit caracter oral şi constau în dialoguri între profesori şi studenţi.

La efortul deosebit pe care îl depuneau aceşti profesori lipsea o idee directoare. Urcarea pe tron a împăratului Constantin al IX-lea Monomahul avea să pună capăt acestei situaţii. Acest împărat a fost înconjurat de oameni cu o pregătire intelectuală deosebită, precum Ioan Xiphilinos, Constantin Lichudes şi Mihail Psellos. Aceste personalităţi intelectuale asociate la conducerea Imperiului trebuiau să aducă o schimbare şi în domeniul vieţii spirituale. La îndemnul lor, Constantin al IX-lea Monomahul a redeschis Universitatea din Constantinopol.

Reorganizată de cezarul Bardas cu două veacuri înainte, în palatul Magnaurei, această înaltă şcoală decăzuse cu totul de vreo sută de ani încoace. Nu este de mirare că în vremea lui Mihail Psellos arabii puteau lua în râs ştiinţa grecilor. Psellos a constatat cu întristare că glorioasa moştenire a Greciei s-a strămutat la asirieni, la mezi şi la egipteni. Universitatea reorganizată şi-a reînceput activitatea în anul 1045, dar nu în palatul Magnaurei, ci în Biserica Sfântului Petru, clădită pe vremea lui Iustinian I de bogatul şi influentul patriciu Petru Barsymes. Universitatea era împărţită în trei facultăţi: drept, filosofie şi retorică ${ }^{6}$.

Prima prioritate a constituit-o Şcoala de drept. Ea a fost complet restaurată, iar la conducerea ei se afla Ioan Xiphilinos, care fusese judecător şi era un jurist cu o mare popularitate în capitală. El a primit titlul de nomophylax (păzitorul legii). Împăratul a instalat această şcoală la mănăstirea Sfântul Gheorghe. În momentul întemeierii Universităţii s-a încins o discuţie puternică în privinţa caracterului învăţământului reorganizat: Mihail Psellos reprezenta ştiinţa în sensul larg al cuvântului, iar Ioan Xiphilinos dreptul. În jurul lor se grupau în tabere adverse aderenţii. Unii, împinşi de

\footnotetext{
${ }^{6}$ Nicolae Bănescu, Chipuri din istoria Bizanţului, antologie, prefaţă şi note de Gheorghe Cronţ, Bucureşti, Edit. Albatros, 1971, p. 153-154.
} 
dorinţa de a împodobi administraţia voiau ca şcoala reînfiinţată să fie una de drept; alţii, iubitori ai ştiinţelor mai respectate, cereau învăţământul filosofic. În faţa acestor dezbateri aprinse, împăratul a căutat să împace amândouă curentele, făcând loc la Universitate atât retoricii şi filosofiei, cât şi ştiinţei legilor ${ }^{7}$. Studiile erau gratuite. Studenţii care proveneau din familii bogate puteau oferi şcolii anumite donaţii, dar fără a primi anumite privilegii. Cei care reuşeau (dintre studenţi) să finalizeze perioada îndelungată a studiilor, primeau un certificat de atestare a studiilor din partea nomophylaxului fără de care nu puteau primi funcţia de notar sau avocat.

În fruntea Şcolii de retorică a fost instalat Ioan Mavropos.

Cursurile la noua Facultate de filosofie, încredinţată lui Mihail Psellos s-au deschis în vechea formulă: trivium (gramatică retorică şi aritmetică), quadrivium (aritmetică, geometrie, astronomie şi muzică). Abia la urmă se studia filosofia însăşi, ca ultimă sinteză a cunoştinţelor ${ }^{8}$.

Învăţământul lui Mihail Psellos a făcut mult zgomot, şi din regiunile cele mai îndepărtate, de peste frontierele Imperiului, lumea venea la catedra sa pentru a se instrui. Împăratul, sensibil la aceasta glorie revărsată asupra tronului său, 1-a distins cu rangul înalt de consul al filosofilor, căpetenia Şcolii superioare. Într-o scrisoare polemică adresată mai târziu patriarhului Mihail Cerularie, învăţatul a subliniat cu ostentaţia sa cunoscută, faima universală legată de numele său:

„Pe celţi şi pe arabi i-am făcut sclavii noştri. Pentru gloria mea s-au coborât aici oameni de pe celălalt continent. Nilul udă într-adevăr pământul egiptenilor, dar sufletul lor îl adapă elocvenţa mea; şi dacă ai întreba pe perşi, pe etiopieni, îţi vor spune că mă cunosc, că m-au admirat şi că mă caută. Acum, de curând, a sosit unul de la hotarele

\footnotetext{
${ }^{7}$ Ibidem, p. 154-155

8 John Julius Norwich, A Short Hystory of Byzantium, Vintage Books, A Division of Random House, Inc. New-York, 1999, p. 230.
} 
Babilonului, mânat de nestăpânita dorinţă de a se adăpa la izvoarele cunoştinţelor mele" ".

Pentru mai bine de două secole înainte, arabii mai degrabă decât grecii au dominat lumea intelectuală. Acum, Bizanţul şi-a redobândit vechea reputaţie şi a devenit din nou un punct important de întâlnire pentru erudiţii din Europa şi din Asia. Pe la sfârşitul domniei lui Constantin Monomahul, noua Universitate dădea mulţi tineri educaţi din care guvernul îşi alegea administratori. Experienţa şi profesionalismul acestor învăţaţi s-a dovedit a fi foarte necesară în anii ce aveau să urmeze ${ }^{10}$.

Universitatea din Constantinopol a funcţionat până în anul 1204. Perioada luptelor pentru putere şi căderea lui Mihail Psellos în dizgraţie au influenţat oarecum nefast învăţământul, dar acest lucru nu înseamnă că Alexios I, cum spune Ana Comnena, a avut un rol determinant la înflorirea învăţământului, pe care 1-ar fi găsit neglijat la urcarea sa pe tron. Afirmaţia Anei Comnena că tatăl ei, împăratul Alexios I, ar fi avut un rol covârşitor în organizarea învăţământului este greşită. Alexios I Comnenul nu a schimbat nimic. Singura sa măsură şcolară a fost înfiinţarea unui orfelinat, în acelaşi timp azil şi şcoală de educare, pe care 1-a organizat în jurul bisericii Sfinţii Petru şi Pavel. Era condus de un proedros şi prevedea un învăţământ elementar.

\section{VI. Învăţământul teologic}

Disputele teologice prilejuite de Marea Schismă din anul 1054 sau de diferitele erezii ne arată că nici teologia nu era mai prejos faţă de celelalte discipline incluse în învăţământul bizantin. Apoi era imposibil ca în Bizanţ să nu existe un învăţământ teologic bine organizat, odată ce filosofia, care era subordonată teologiei, (aşa cum am văzut în cazul lui Ioan Italos) se studia în Universitate.

\footnotetext{
${ }^{9}$ Nicolae Bănescu, op. cit., p. 156.

${ }^{10}$ John Julius Norwich, op. cit., p. 231.
} 
Aşa cum administraţia bizantină era formată din oameni anume instruiţi pentru posturile pe care le ocupau şi Biserica avea nevoie de slujitori care să cunoască bine problemele teologice şi disciplinare, care stăteau la baza organizării şi existenţei sale pământeşti, în acel raport de complementaritate cu statul bizantin, cunoscut sub denumirea de sintonie bizantină

Aceste cerinţe le satisfăcea Şcoala Patriarhală din Constantinopol. Originea ei este legată de epoca Sinoadelor Ecumenice, dar abia din secolul al IX-lea a început să joace un rol important în viaţa intelectuală şi teologică a capitalei. Probabil că prestigiul ei a fost în creștere după decăderea Universităţii în secolul al X-lea. În secolele XI-XII, prin dascălii săi şi prin calitatea studiilor. Şcoala Patriarhală era pe picior de egalitate cu fiecare dintre şcolile care alcătuiau Universitatea imperială reorganizată.

Conducerea acestei instituţii teologice de prestigiu o avea profesorul ecumenic, cu precizarea că epitetul de ecumenic nu arătă aici dependenţa de patriarh. Acest titlu care însemna universal era folosit în secolul al VI-lea în cadrul şcolii de drept din Beirut. Profesorul ecumenic era rector şi profesor principal şi totodată însărcinat cu interpretarea sau exegeze Evangheliilor. În afară de profesor ecumenic, toţi ceilalţi profesori, care activau în cadrul Şcolii Patriarhale, aveau un anumit rang în ierarhia demnitarilor patriarhali.

În privinţa programului de studiu, acesta cuprindea în prima fază învăţământul general, pe cale Biserica 1-a pretins totdeauna viitorilor slujitori şi preoți. Era numit invățământul uşii şi trebuia să se teacă prin el înainte de intrarea în cel teologic. Se punea accentul pe studiul gramaticii, al retoricii şi chiar al filosofiei. Pentru predarea acestor discipline erau profesori anume pregătiţi ca să-i poată învăţa pe elevi tainele disciplinelor respective. În afara obligaţiilor profesorale, maeştrii de retorică erau oratori ai Curţii imperiale şi ţineau discursuri în faţa basileului la marile sărbători de peste an.

Învăţământul teologic propriu-zis (a doua fază) avea trei profesori cu rang de didaskalos: profesorul de exegeză a Evangheliei (rectorul), profesorul de exegeză a Apostolului şi Epistolelor şi profesorul de exegeză a Psaltirii. Profesorii ecumenici au avut un rol 
important în disputele teologice. Printre cei mai celebri au fost: Pavel Everghetinul ${ }^{11}$, diaconii Mihail, Nichifor Basilakes, Vasilios, etc. În secolul al XII-lea, la Şcoala Patriarhală a predat şi Eustaţiu, care a ajuns apoi mitropolit al Tesalonicului. Una din scrierile vremii descrie în cuvinte mişcătoare profesoratul său:

„Lecţiile lui Eustathios erau pline de miere ca nişte izvoare de nectar, astfel că vorbele lui pătrundeau în cămările cele mai tainice din inima ascultătorilor săi şi rămâneau neşterse în calea uitării. În lecţiile sale zilnice, el nu se limita să aplice cartea pe care o avea în mână, iar interpretarea lui nu ţinea doar să clarifice ceea ce era obscur. Adăuga numeroase alte materiale extrase din cărţi, nu pentru a-şi face un merit din nişte digresiuni inoportune, ci pentru că era inspirat. Dacă vreun student cu o carte de poezie sub braț îi cerea lămuriri despre regulile metricii, sau despre ritmurile armoniei, sau despre etimologia cuvintelor, sau despre mitologia anticilor, se concentra ca un veritabil iniţiat asupra acestor subiecte, deprins în orice moment cu secretele lor adânci. Câţi n-au ajuns la el de copii, conduşi fiind apoi spre maturitate, nu numai cu laptele matern, ci şi cu hrana solidă a învăţăturii ! ... Câţ̧i nu se socoteau că stăpânesc gramatica încât să o predea şi altora, dar când se măsurau cu unitatea lui de măsură înţelegeau cât de puțin ştiau într-adevăr ! Câţi nu păreau excelent pregătiţi în filosofie, până când sau confruntat cu el, învăţând să-şi cunoască astfel propria ignoranţă, renunţând la opinia lor cu privire la cunoaştere !"12

Se poate observa, deci, întrepătrunderea tot mai mare dintre gramatică, retorică şi filosofie, în prestaţia la catedră a celor mai buni profesori ai epocii, care a fost una a inovaţiei şi a cercetării ${ }^{13}$.

\footnotetext{
${ }^{11}$ Virgil Cândea, Un dascăl icumenic de neuitat: Cuviosul Pavel Everghetinul (Ctitoria şi scrierile sale), în Mitropolia Olteniei, anul VIII, nr. 8-9, augustseptembrie, 1956, p. 456-481.

${ }^{12}$ Eusthatios, Cuvântări, apud. Robert Browning, op. cit., p. 127-128.

${ }^{13}$ Robert Browning, op. cit., p. 127-128.
} 


\section{Concluzii}

Se poate spune că, în general pregătirea intelectuală în Bizanţ se bucura de o mare apreciere, date fiind şi finalităţile ascensiunea în ierarhia statului sau în cea eclesiastică. Pe lângă valoarea lor intrinsecă, generată de competenţa în educaţie, se adaugă o reecunoaştere publică, intelectualii având sarcini în diverse sectoare de activitate ale Imperiului.

Pe fondul marii epopei bizantine derulate în timpul dinastiei macedonene, se remarcă faptul că cultura bizantină a evoluat sub impulsul măsurilor de reorganizare a învăţământului întreprinse de cezarul Bardas, începând din anul 863. În acest context pregătirea intelectuală a omului de rând era mult mai apreciată şi mai răspândită decât în Occident. Aceasta şi pentru că învăţământul putea asigura chiar şi celor cu origine mai modestă o carieră frumoasă şi accesul în funcţiile cele mai înalte în stat şi în ierarhia ecleziastică. Marile oraşe aveau şcoli renumite şi biblioteci bogate în manuscrise şi cărţi de mare valoare.

Învăţământul era în bună măsură privat, deci cu taxe, care nu erau însă insurmontabile, ceea ce asigura o relativă accesibilitate la cunoaştere. Învăţământul secundar era concentrat în capitală. La vârsta de 10-11 ani un copil putea intra într-un didaskaleion sau paideuterion pentru a primi noţiuni de cultură generală. Fiecare școală avea în principiu un profesor, maistor ajutat de un proximos. În acest sistem erau admişi elevi de toate vârstele, iar durata studiilor era de 6-7 ani.

Fondul programei era trivium (gramatica, poezia şi retorica). În acest ciclu, profesorii urmăreau perfecţionarea limbajului şi formarea viitorilor funcţionari civili sau bisericeşti. Localizarea şcolilor impunea adesea intervenţia Bisericii: ele se situau în interiorul clădirilor ecleziastice, în apropierea unei biserici care dădea şi numele şcolii: a Maicii Domnului, a Sfântului Teodor, a celor patruzeci de mucenici sau cea mai celebră la vremea aceea, a Sfântului Petru, unde predau simultan Mihail Psellos, Ioan Xifilinos şi Nicetas Gramaticul. 
Fără îndoială, şcolile Bizanţului din această perioadă au avut o contribuţie determinantă şi la creşterea calitativă a diplomaţiei imperiale (împăratul Teofil I 1-a trimis pe Ioan Gramaticul ca ambasador în califatele arabe, la fel cum împăratul Mihail al III-lea ia trimis pe Fotie şi pe fraţii Constantin-Chiril şi Metodie, în diferite misiuni diplomatice).

Modelul educaţional bizantin este, fără îndoială, produsul unei incomprehensiuni culturale: greco-romană şi creştină, întâlnire care se traduce într-o osmoză determinată de puterea de adaptabilitate a culturii greco-romane şi optimismul noii credinţe creştine. Astfel, educaţia bizantină s-a dovedit a fi produsul vizibil al acestei întâlniri.

Într-un astfel de context cultural, cu implicaţii ale modelelor educaţionale şi ale rezultatelor până la nivelurile cele mai înalte ale societăţii bizantine, contribuţia învăţământului a fost majoră.

\section{Bibliografie}

1. Bănescu, Nicolae, Chipuri din istoria Bizanţului, antologie, prefaţă şi note de Gheorghe Cronţ, Bucureşti, Edit. Albatros, 1971.

2. Browning, Robert, Dascălul, în Omul bizantin, volum coordonat de Guglielmo Cavallo, traducere de Ion Mircea, postfaţă de Claudia Tiţa-Mircea, Iaşi, Edit. Polirom, 2000, p. 111-136.

3. Cândea, Virgil, Un dascăl icumenic de neuitat: Cuviosul Pavel Everghetinul (Ctitoria şi scrierile sale), în Mitropolia Olteniei, anul VIII, nr. 89, august-septembrie, 1956, p. 456-481.

4. Norwich, John Julius, A Short Hystory of Byzantium, Vintage Books, A Division of Random House, Inc. New-York, 1999.

5. Vasiliev, A. A., Istoria Imperiului Bizantin, traducere şi note de IonuţAlexandru Tudorie, Vasile-Adrian Carabă, Sebastian Laurenţiu-Nazâru, studiu introductiv Ionuţ-Alexandru Tudorie, Iaşi, Edit. Polirom, 2010. 